\title{
Influences of Sodium Lignosulfonate and High-Volume Fly Ash on Setting Time and Hardened State Properties of Engineered Cementitious Composites
}

\author{
Anggun Tri Atmajayanti ${ }^{1}$, Chung-Chan Hung ${ }^{1, *}$, Terry Y. P. Yuen ${ }^{2}$ and Run-Chan Shih ${ }^{3}$ \\ 1 Department of Civil Engineering, National Cheng Kung University, 1 University Road, \\ Tainan City 701, Taiwan; anggun.tri.atmajayanti@gmail.com \\ 2 Department of Civil Engineering, National Yang Ming Chiao Tung University, Hsinchu 300, Taiwan; \\ terryyyp@nctu.edu.tw \\ 3 Department of Civil Engineering, National Central University, Taoyuan City 320, Taiwan; \\ fofo_1018@hotmail.com \\ * Correspondence: cchung@mail.ncku.edu.tw; Tel.: +886-6-2757575 (ext. 63130); Fax: +886-6-2370804
}

Citation: Atmajayanti, A.T.; Hung, C.-C.; Yuen, T.Y.P.; Shih, R.-C.

Influences of Sodium Lignosulfonate and High-Volume Fly Ash on Setting Time and Hardened State Properties of Engineered Cementitious Composites. Materials 2021, 14, 4779. https://doi.org/10.3390/ma14174779

Academic Editor: Doo-Yeol Yoo

Received: 9 June 2021

Accepted: 20 August 2021

Published: 24 August 2021

Publisher's Note: MDPI stays neutral with regard to jurisdictional claims in published maps and institutional affiliations.

Copyright: ( $\odot 2021$ by the authors Licensee MDPI, Basel, Switzerland. This article is an open access article distributed under the terms and conditions of the Creative Commons Attribution (CC BY) license (https:// creativecommons.org/licenses/by/ $4.0 /)$.

\begin{abstract}
Engineered Cementitious Composites (ECC) exhibit high ductility accompanied by multiple narrow cracking behavior under uniaxial tension. The study experimentally investigated the influence of sodium lignosulfonate and high volumes of fly ash (HVFA) on the properties of fresh and hardened ECC, with the experimental variables including the amounts of fly ash, polyvinyl alcohol (PVA) fibers, and sodium lignosulfonate. The test results were discussed extensively in terms of the initial and final setting times, compressive and tensile behavior, and drying and autogenous shrinkage. The results indicated that the initial and final setting times of ECC were increased along with the sodium lignosulfonate content of up to $1 \%$. The drying shrinkage development was governed by the first 14 days. In addition, the major autogenous shrinkage developed for more than 28 days. The amounts of fly ash, PVA fibers, and sodium lignosulfonate considerably impacted the autogenous shrinkage. Moreover, it was found that the dosage of sodium lignosulfonate at $0.5 \%$ of the weight of Portland cement optimally reduced the shrinkage and enhanced the tensile strain capacity for ECC.
\end{abstract}

Keywords: ECC; fly ash; setting time; autogenous shrinkage; drying shrinkage; sodium lignosulfonate

\section{Introduction}

High-performance fiber-reinforced cementitious composites (HPFRCCs) are characterized by pseudo-strain-hardening behavior accompanied by multiple narrow cracks when under uniaxial tension. They have attracted the increasing attention of researchers and engineers to a wide range of innovative applications in structural engineering due to their advantageous mechanical properties and durability [1-11]. Engineered Cementitious Composites (ECC), a unique class of HPFRCCs, feature a large strain capacity with selfcontrolled crack width [12-23]. Its tensile strain capacity can reach more than 3\% [17-26], and its average crack width was reported to be less than $60 \mu \mathrm{m}$ when the tensile strain demand was less than 1\% [14]. The high strain capacity and multiple hairline cracking behavior of ECC are achieved by tailoring the fracture toughness of the matrix by excluding coarse aggregate and limiting the fine sand content $[27,28]$. Compared to traditional concrete materials, ECC usually contains a considerably higher cement content and lower aggregate content, which could aggravate drying and autogenous shrinkage. In particular, it was showed that the drying shrinkage strain of ECC can reach as high as $1200 \times 10^{-6}$ to $1800 \times 10^{-6}$ [29].

The shrinkage behavior is an important factor affecting the durability of cement-based materials [2,7,15,30-39]. Xinqi et al. [28] experimentally showed that the shrinkage of ECC at 14 days of age reached $90 \%$ of the shrinkage at 28 days of age. They concluded that the 
crack resistance of ECC was significantly affected by the shrinkage behavior within the age of 14 days. Sahmaran and Li. [40] used saturated lightweight fine aggregate in ECC as an internal curing agent. The autogenous shrinkage of ECC was reduced by $67 \%$ through the replacement of $20 \%$ silica sand with saturated lightweight fine aggregate. Zhang et al. [41] showed that the replacement of Type I Portland cement with low-shrinkage cement in ECC effectively reduced the shrinkage, with the 28-day drying shrinkage strain of only $109 \times 10^{-6}$ to $242 \times 10^{-6}$. Nath and Sarker [27] indicated that partially replacing Portland cement with FA did not warrant a lower drying shrinkage unless the free moisture content in the matrix was reduced. Wang and Li [42] used FA and bottom ash in ECC to improve the sustainability and strain-hardening behavior of ECC. The results demonstrated a robust tensile strain capacity of $3-4 \%$ and tensile strength above $4.5 \mathrm{MPa}$ while material sustainability indexes were significantly improved.

Due to the relatively low water-binder ratio of ECCs and the absence of coarse aggregate, high-range water reducer (HRWR) or superplasticizer is often added to the mixture to achieve the desired workability. Among different types of water-reducing agents, lignosulfonates (LSs), which can be a by-product derived from the sulfite wood-pulping process [43], has been widely used due to its relatively low price [44] and effectiveness in reducing the required water content for cement-based composites [45]. While the inclusion of lignosulfonate (LS) generally led to a higher compressive strength for concrete due to the lower amount of water needed [46-49], Topcu and Atesin [50] showed that the dosage of LS of greater than 1\% reduced the compressive strength of concrete.

In addition to reducing the required water, LS is also known as an effective retarder for fresh concrete $[47,51,52]$. The mechanisms of OPC hydration retardation are due to the interaction of the $\mathrm{Ca}^{2+}$ ions with the negative charged anions of LS and the inhibited conversion of needle-shaped AFt (ettringite) to AFm (monosulfate) under the presence of LS [53]. While the reduced availability of $\mathrm{Ca}^{2+}$ decreases the formation of crystalized calcium hydroxide $(\mathrm{CH})$, a hydrophobic film of the LS anion adsorbed onto the cement particle surface would restrict the water access to the particles. On the other hand, the LS anions absorbed onto AFt would also inhibit its further crystallization to AFm. Vikan [54] concluded that LS was more effective than polyacrylate and naphthalene sulfonate formaldehyde in prolonging the setting time. Topcu and Atesin [50] demonstrated that the addition of LS at 5\% extended the initial and final setting times for $2 \mathrm{~h}$ and $6 \mathrm{~h}$, respectively. Cabrera et al. [55] showed that the addition of LS led to a lower plastic shrinkage due to the reduced surface tension.

Despite the popularity of LS in ordinary cement concrete, there is still a knowledge gap in the effect of LS on the properties of fresh and hardened ECC. In addition, the studies on the autogenous shrinkage behavior of ECC with high volumes of FA (HVFA-ECC) were scarce in the literature. Therefore, a systematic experimental study was conducted to investigate the influences of fly ash, PVA fibers, and lignosulfonate in the properties of fresh and hardened ECC. The results were discussed in terms of the initial and final setting times, compressive and tensile behavior, and drying and autogenous shrinkage.

\section{Experimental Program}

\subsection{ECC Mixtures and Preparation}

Eight ECC mixtures were developed to assess the influence of varying amounts of FA, short fibers, and sodium lignosulfonate (NLS) in the properties of ECC. The water-to-binder $(\mathrm{w} / \mathrm{b})$ ratio was 0.35 for all ECC mixtures. The mixture proportions are listed in Table 1. The components included Type I ordinary Portland cement (OPC), Class F fly ash (FA), silica sand (SS) with particle sizes ranging from $0.105 \mathrm{~mm}$ to $0.210 \mathrm{~mm}$, polycarboxylate superplasticizer (PCE), water, NLS, and polyvinyl alcohol (PVA) fibers. The length and diameter of the PVA fibers were $12 \mathrm{~mm}$ and $39 \mu \mathrm{m}$, respectively. The fibers had a tensile strength of $1600 \mathrm{MPa}$, a density of $1300 \mathrm{~kg} / \mathrm{m}^{3}$, an elastic modulus of $41 \mathrm{GPa}$, and a maximum elongation ratio of $6 \%$. The adopted NLS mainly consisted of silicon dioxide, calcium oxide, sulfate, and aluminum oxide. 
Table 1. Mixture proportions of ECC by weight.

\begin{tabular}{cccccc}
\hline ECC Material & OPC & FA & SS & Fiber * & NLS \\
\hline FA1.2-2\%-0\% & & 1.2 & & & \\
FA1.7-2\%-0\% & & 1.7 & & & \\
FA2.2-2\%-0\% & & 2.2 & & 0 & 0 \\
FA1.2-0\%-0\% & 1 & & 0.8 & 1 & \\
FA1.2-1\%-0\% & & 1.2 & & 2 & 0.005 \\
FA1.2-2\%-0.5\% & & & & 0.02 \\
FA1.2-2\%-1\% & & & & & \\
FA1.2-2\%-2\% & & & & & \\
\hline
\end{tabular}

* The cement content is $382 \mathrm{~kg} / \mathrm{m}^{3}$ for all mixtures, and PVA fiber is proportioned by volume $V_{f} \%$.

The mixing procedure followed the steps suggested by Hung et al. [25] that evaluated the medium-term self-healing of ECC with varying amounts of fly ash and exposure durations. All dry particles were pre-mixed in a Hobart mixer. Then, the chemical additives and half of the required water were mixed and soon added to the mixer [56]. After that, the PVA fibers and the remaining water were added to the mixer. Table 2 shows the detailed compositions of adopted NLS and FA. The name of an ECC mixture in Table 1 consists of three parts: the FA-to-OPC (FA/C) ratio (by weight), volume fraction $\left(V_{f}\right)$ of PVA fibers, and NLS-to-OPC ratio (by weight). For example, FA1.2-2\%-0.5\% represents the ECC mixture with the FA/C ratio of $1.2, V_{f}=2 \%$, and the NLS-to-OPC ratio of $0.5 \%$.

Table 2. Compositions (wt. \%) of FA and NLS.

\begin{tabular}{cccccccccccc}
\hline & $\mathbf{C a O}$ & $\mathrm{SiO}_{2}$ & $\mathrm{Al}_{2} \mathbf{O}_{\mathbf{3}}$ & $\mathrm{Fe}_{2} \mathbf{O}_{\mathbf{3}}$ & $\mathbf{P}_{\mathbf{2}} \mathbf{O}_{\mathbf{5}}$ & $\mathbf{K}_{\mathbf{2}} \mathbf{O}$ & $\mathrm{TiO}_{2}$ & $\mathbf{M g O}$ & $\mathbf{N a}_{2} \mathbf{O}$ & $\mathbf{S O}_{3}$ & $\mathbf{N H}_{4}{ }^{+}$ \\
\hline FA & 4.37 & 64.69 & 19.03 & 8.34 & 0.01 & 2.01 & 0.86 & 2.31 & 1.22 & 0.12 & 0.07 \\
NLS & 37.04 & 50.78 & 3.57 & 0.10 & 0.05 & 0.05 & - & 1.72 & 2.62 & 3.93 & - \\
\hline
\end{tabular}

\subsection{Evaluation Methods}

2.2.1. Initial and Final Setting Time

The setting time of the fresh ECC was obtained using penetration tests in accordance with ASTM C403M-08 Standard Test Method for Time of Setting of Concrete Mixtures by Penetration Resistance [57], as shown in Figure 1.

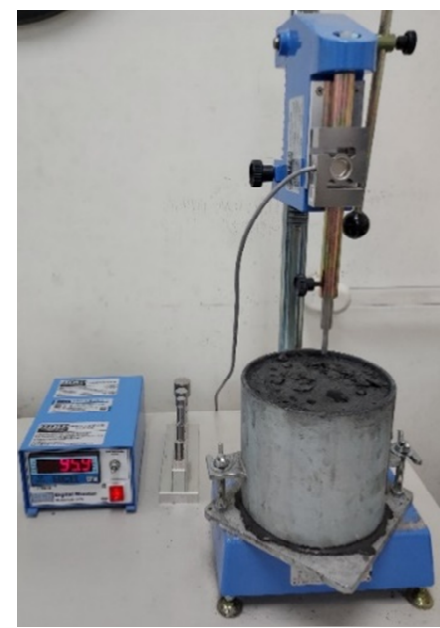

Figure 1. Evaluation of setting time by penetration resistance.

The ambient temperature was controlled to be $20 \pm 2{ }^{\circ} \mathrm{C}$ throughout the tests. Initial and final setting times were determined as the duration required for the penetration resistance to reach 3.5 and $27.6 \mathrm{MPa}$, respectively. 


\subsubsection{Drying and Autogenous Shrinkage}

The drying shrinkage of ECC was examined using four prismatic samples with dimensions of $25 \times 25 \times 285 \mathrm{~mm}^{3}$ according to ASTM C490M-17 Standard Practice for Use of Apparatus for Determination of Length Change of Hardened Cement Paste Mortar and Concrete [58]. Before the material samples were cast, two steel gauge studs were inserted at both ends of the mold, which led to a gauge length of $250 \mathrm{~mm}$ (comply with ASTM C490M-17), as shown in Figure 2a. The samples were demolded $24 \mathrm{~h}$ after casting and then cured for 3 days in water at $20 \pm 2{ }^{\circ} \mathrm{C}$. The length of the samples after 3 days of water curing was taken as the initial length. After that, the samples were placed in a constant humidity incubator with a controlled $50 \% \mathrm{RH}$ and $20 \pm 2{ }^{\circ} \mathrm{C}$. Then, the length of the samples was measured daily in the first 7 days and then every week until the 90th day. For determination of the autogenous shrinkage, another four prismatic samples were prepared and examined in a similar procedure as for the drying shrinkage, except the molds were sealed with aluminum foils as soon as the casting was done to prevent the loss of moisture within the samples due to evaporation.

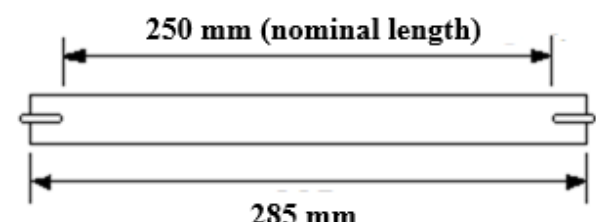

(a)

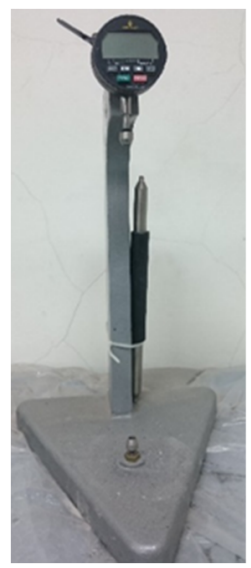

(b)

Figure 2. Evaluation of shrinkage: (a) Shrinkage specimen; (b) Digital length comparator.

A digital length comparator, as shown in Figure $2 b$, with a measurement range of $15.2 \mathrm{~mm}$ and a resolution of $2.54 \mu \mathrm{m}$ was adopted to measure the length of the samples. The measurement was made by sliding the feet of the comparator to contact the top of each gauge stud. The shrinkage strain of the samples was calculated as $\varepsilon_{s}=\left(L_{0}-L_{t}\right) / G$, where $L_{0}$ and $L_{t}$ are the lengths measured at the initial condition and the specified time, and $G$ is the gauge length.

\subsubsection{Compressive and Tensile Properties}

The compressive strength of the ECC materials was examined using standard cylindrical specimens with a diameter of $100 \mathrm{~mm}$ and a height of $200 \mathrm{~mm}$ and a procedure consistent with ASTM C39 Standard Test Method for Compressive Strength of Cylindrical Concrete Specimens [59]. The tensile properties of the ECC were determined using uniaxial tensile tests on dog-bone-shaped specimens based on the Japan Society of Civil Engineers (JSCE) Recommendations for Design and Construction of High Performance Fiber Reinforced Cement Composites with Multiple Fine Cracks (HPFRCC) [60] with geometrical dimensions, shown in Figure 3. Before the tensile tests, thin aluminum plates were glued to both ends of the dog-bone-shaped specimens for the loading system to effectively grip the specimen. Two linear variable displacement transducers (LVDTs) were placed on both sides of the specimen to measure the tensile deformation of an $80 \mathrm{~mm}$ long-gauge region. Both compressive and tensile tests were carried out using a displacement control procedure with a consistent loading rate of $0.5 \mathrm{~mm} / \mathrm{min}$. For the preparation of the specimens, they were 
demolded $24 \mathrm{~h}$ after casting. Then, the specimens were cured in water until one day prior to the tests, which was followed by air curing at a controlled temperature of $20 \pm 2{ }^{\circ} \mathrm{C}$.

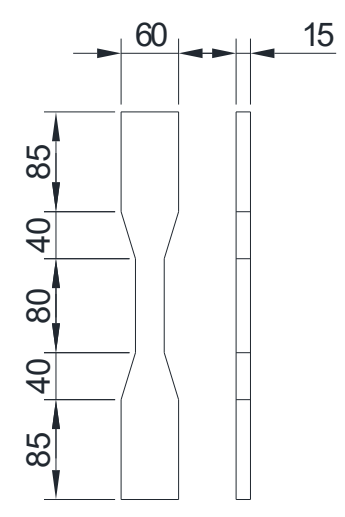

(a)

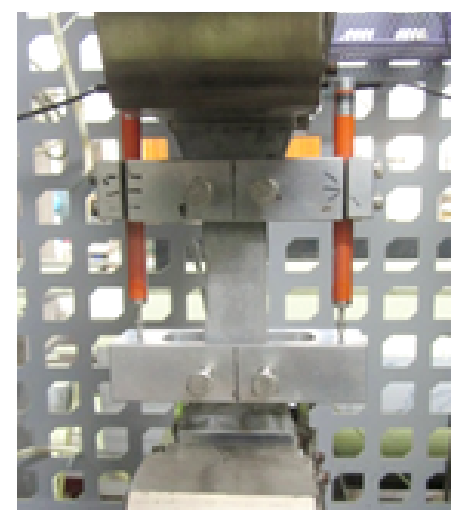

(b)

Figure 3. Tensile test on the dog-bone-shaped specimen: (a) Specimen dimensions; (b) Test setup.

\section{Experimental Results and Discussions}

\subsection{Setting Time}

Figure 4 shows the relationship between the penetration resistance and time for the series of FA1.2-2\% mixtures with different amounts of NLS.

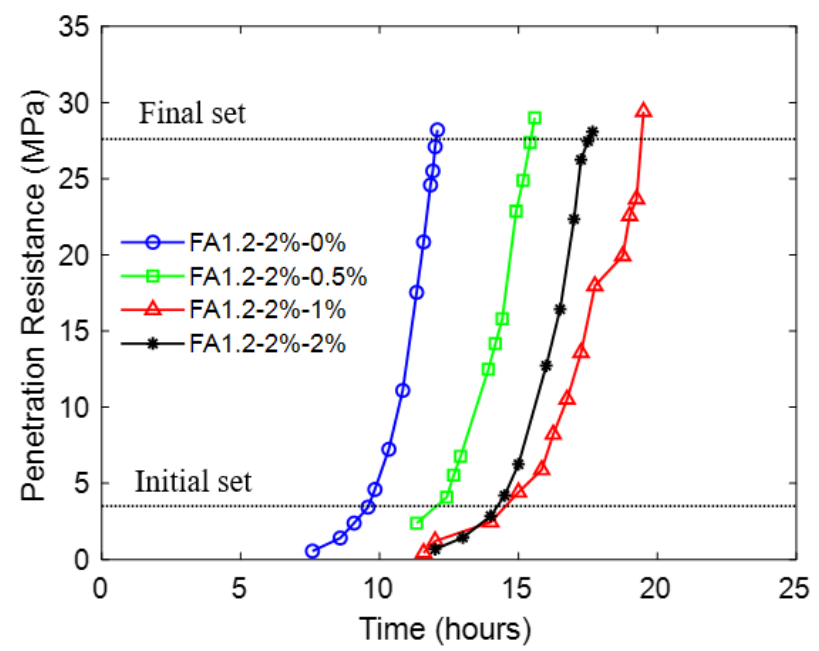

Figure 4. Influence of NLS on the penetration resistance of ECC.

The results show that increasing the NLS dosage from $0 \%$ to $1.0 \%$ increased the initial setting time from $9.6 \mathrm{hrs}$ to $15.5 \mathrm{hrs}$ and the final setting time from $12.1 \mathrm{~h}$ to $19.7 \mathrm{~h}$. However, a further increase in NLS from $1.0 \%$ to $2 \%$ had negligible influence in the initial setting time and reduced the final setting time. The duration between the initial and final sets also had a similar trend with the NLS content. This result implies that when the NLS content was increased from $0 \%$ to $1.0 \%$, more flocculated cement grains were disassembled, and hence more entrapped water was released. When the NLS content was more than $1 \%$, flocculated cement grains were nearly fully disassembled, and the initial setting time remained essentially unchanged with the addition of NLS. The reduction of the final setting time of the mixture with $2.0 \%$ NLS would be explained by the increase in particle surface area with increasing NLS dosage [56]. Hence, when the hydration products began to develop after the initial set, the larger surface area could provide more nucleation sites for the crystallization. 


\subsection{Drying Shrinkage} ratios.

Figure 5 shows the drying shrinkage of the ECC with $V_{f}=2 \%$ and different FA/C

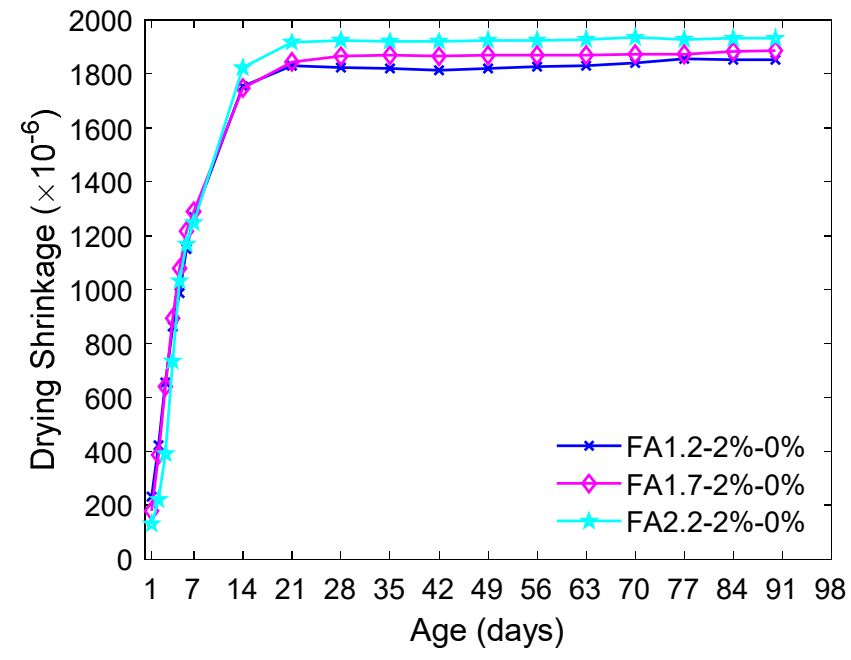

Figure 5. Influence of FA content in the drying shrinkage of ECC.

In the early stage, the drying shrinkage increased steadily and rapidly to about $1200 \mu$ at 7 days. After that, although the shrinkage growth rate slightly reduced, the drying shrinkage continued to increase to about $1800 \mu$ at 14 days, which was approximately $90 \%$ of the 90 -day drying shrinkage. Then, the drying shrinkage gradually stabilized and essentially became constant after 20 days. Overall, increasing the FA/C ratio from 1.2 to 2.2 had a negligible influence on the drying shrinkage before the 14th day. At 90 days, it slightly increased the total drying shrinkage from $1852 \mu$ to $1932 \mu$. The increasing drying shrinkage due to the higher FA/C ratio could be attributed to multiple factors. Firstly, the capillary stress in the ECC with a higher FA/C ratio could be higher due to the refined microscopic pore structure $[29,61,62]$, which increased the loss of water from capillary voids [62]. Moreover, a higher FA/C ratio tended to reduce the elastic modulus of the solid skeleton and the bond between PVA fibers and the surrounding matrix [42], thus leading to a higher drying shrinkage [63].

The influence of $V_{f}$ in the drying shrinkage of ECC is illustrated in Figure 6.

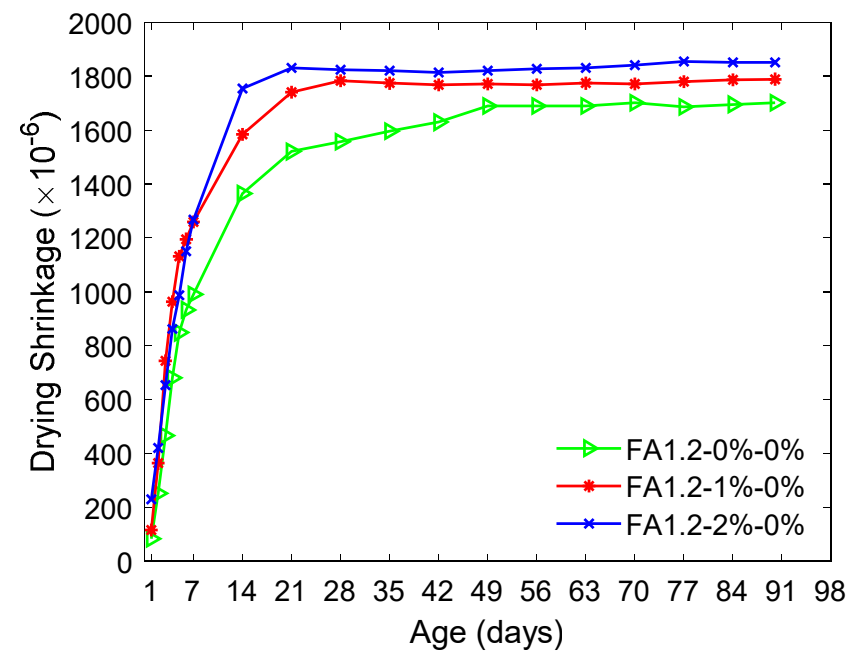

Figure 6. Influence of fiber content in the drying shrinkage of ECC. 
It can be seen that the ECC with a greater amount of PVA fibers appeared to have a higher shrinkage rate prior to the 14th day. At the age of 90 days, increasing $V_{f}$ from $0 \%$ to $2 \%$ slightly increased the drying shrinkage of ECC from $1702 \mu$ to $1852 \mu$, about a $10 \%$ magnification. This could be due to the increased entrained air [64] following the increase in fiber content and the entrained air would lead to larger shrinkage [65].

Figure 7 shows the influence of NLS on the drying shrinkage of ECC. The inclusion of an NLS dosage of $0.5 \%$ led to an approximate $10 \%$ reduction in the drying shrinkage. Bishop and Barron [66] experimentally showed that the presence of LS accelerated ettringite formation due to the hydration of $\mathrm{C}_{3} \mathrm{~A}$. Moreover, LS involves the formation of a semipermeable layer on cement grains, which could slow down the diffusion of pore solution [66] and alleviate volume reduction due to drying shrinkage. Because of these possible mechanisms, the drying shrinkage was reduced after the inclusion of NLS at $0.5 \%$. Nevertheless, the beneficial effect in reducing the drying shrinkage gradually decreased with the increased NLS content from $0.5 \%$ to $2 \%$. For the ECC with $2 \%$ NLS, its drying shrinkage was similar to the result of the ECC without NLS. It is noted that the "consumption" of LS by cement grains forming the semipermeable layer is the largest at a specific LS dosage $[43,56]$. After that dosage, the uptake of LS by the cement grains as well as the semipermeable layer will decrease. Hence, among the considered mixtures, $0.5 \%$ NLS would apparently lead to the maximum LS uptake by cement. Moreover, high dosage LS can also lead to increased air entrainment [56] that can similarly result in high shrinkage [65].

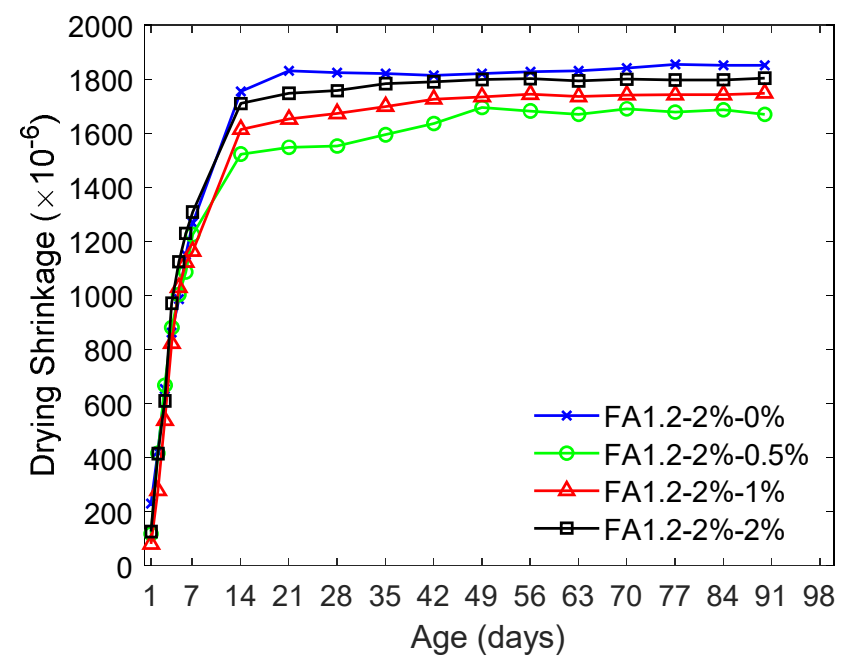

Figure 7. Influence of NLS content in the drying shrinkage of ECC.

\subsection{Autogenous Shrinkage of ECC}

Figure 8 shows the impact of the FA/C ratio on the autogenous shrinkage of ECC at different ages. It can be seen that the autogenous shrinkage of ECC rapidly developed within 28 days. Then, the autogenous shrinkage of ECC became relatively stable, especially for the ECC with a higher FA/C ratio. The comparison results of Figures 5 and 8 indicated that ECC had a substantially higher drying shrinkage than the autogenous shrinkage at the age of 90 days. While increasing the FA/C ratio from 1.2 to 2.2 only slightly increased the drying shrinkage (Figure 5), it considerably reduced the 90-day autogenous shrinkage from about $640 \mu$ to $220 \mu$ (Figure 8), approximately a $65 \%$ reduction. 


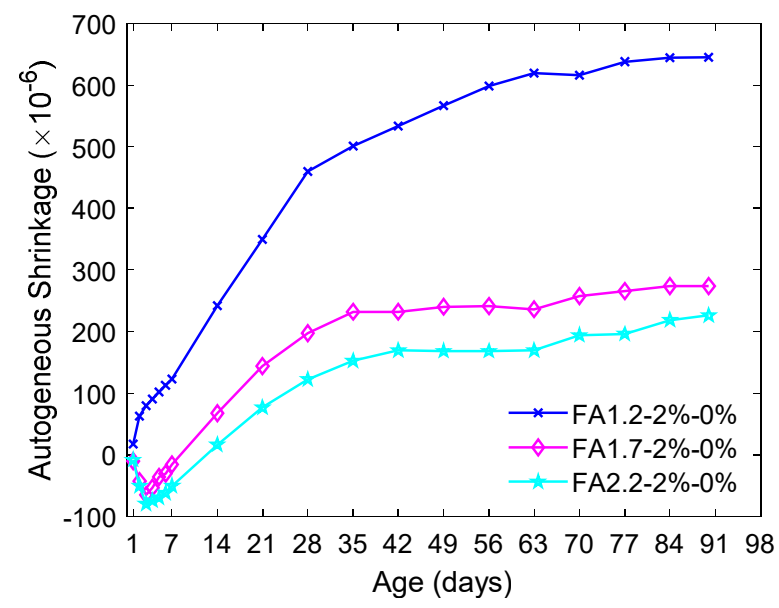

Figure 8. Autogenous shrinkage of ECC with different FA contents.

Overall, a high FA/C ratio led to an effective reduction in the autogenous shrinkage of ECC due to the reduced contribution from cement hydration caused by a lowered cement content. It is also widely known that using FA to partially replace cement is able to reduce the water demand in concrete due to the ball bearing effect of round FA particles. As a result, more free water retained in the ECC when the FA/C ratio was higher, which helped cover the surfaces of unhydrated particles and reduce self-desiccation. Moreover, autogenous shrinkage is the result of the change in the macro volume of cement paste, which is dependent on the volumetric percentage of pores. A higher FA/C ratio reduced the volumetric percentage of the pores due to enhanced pozzolanic reaction $[67,68]$, thus reducing the autogenous shrinkage of ECC.

Figure 9 presents the effect of fiber contents on the autogenous shrinkage of ECC with $F A / C=1.2$. The autogenous shrinkage increased along with the fiber content. Notably, while the 90-day autogenous shrinkage was increased by about $20 \%$ when $V_{f}$ was increased from $0 \%$ to $1 \%$, it was substantially magnified by approximately $100 \%$ when $V_{f}$ was further increased to $2 \%$. This can be attributed to the presence of hydrophilic PVA fibers that absorbed some free water from cement and hydration products [69], thus aggravating the self-desiccation. In addition, air voids and porosity in fiber-reinforced concrete increased rapidly along with the fiber content [70], which could intensify the change in the capillary pressure induced by self-desiccation in the cement matrix.

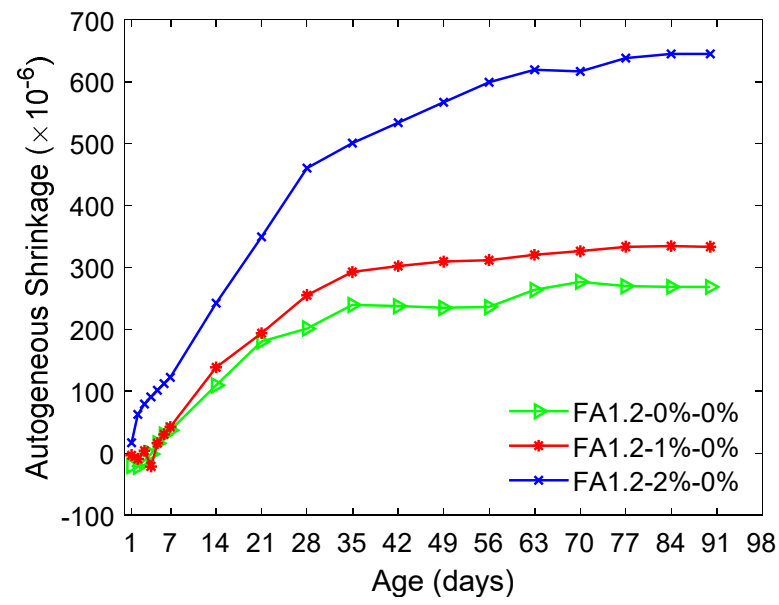

Figure 9. Autogenous shrinkage of ECC with different fiber contents.

Figure 10 shows that the inclusion of NLS reduced the autogenous shrinkage of the FA1.2-2\% mixtures. This was due to the inclusion of NLS-retarded cement hydration [71], 
which reduced the hydration heat and the autogenous shrinkage [72]. The 90-day autogenous shrinkage of the FA1.2-2\% mixtures ranged between $300 \mu$ and $650 \mu$ when the dosage of NLS was $0-2 \%$. The inclusion of $0.5 \%$ NLS led to the least autogenous shrinkage, which could be attributed to the slowed cement hydration due to the semipermeable layer on cement grains due to the LS uptake as explained above. It greatly reduced the 90-day autogenous shrinkage to around $300 \mu$, about a $50 \%$ reduction compared to the case when there was no NLS.

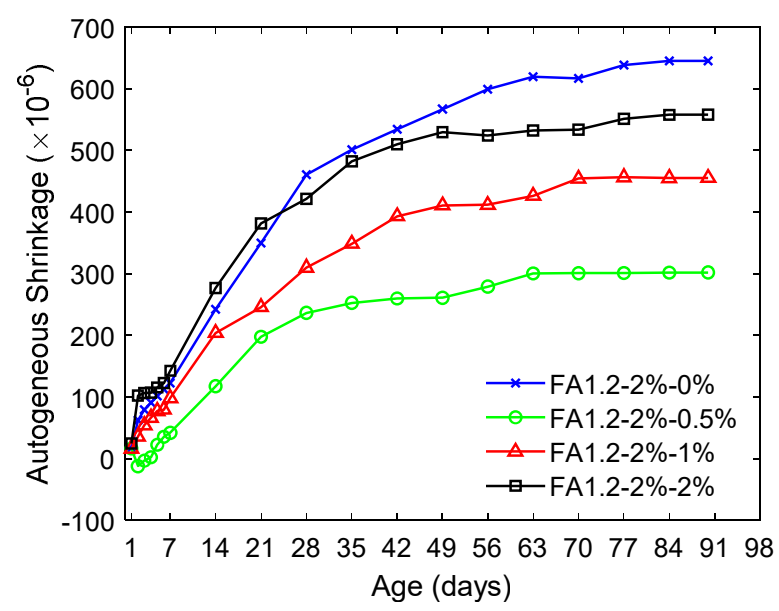

Figure 10. Autogenous shrinkage of ECC with different amounts of NLS.

\subsection{Mechanical Properties of the ECC Materials}

\subsubsection{Compressive Strength}

Figure 11 shows that a higher FA/C ratio led to a lower compressive strength of ECC at both 28 and 90 days due to the reduced contribution from cement hydration caused by a lowered cement content. Increasing the FA/C ratio from 1.2 to 2.2 caused the 28-day compressive strength to substantially decrease from $62 \mathrm{MPa}$ to $27 \mathrm{MPa}$. Nevertheless, the ECC with a higher FA/C ratio had a more substantial strength development at the later age due to the pozzolanic reaction. As a result, the reduction in the compressive strength due to the use of a higher FA/C ratio became less significant when the age was increased to 90 days.

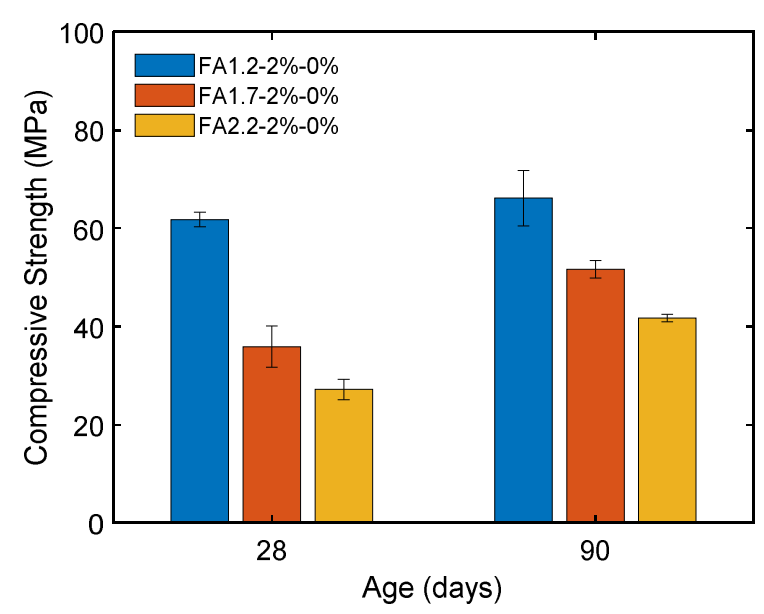

Figure 11. Compressive strengths of ECC with different amounts of FA.

Figure 12 shows the effect of fiber content on the compressive strength of ECC. It can be seen that the compressive strength was generally higher with a greater $V_{f}$. Compared to the case with $V_{f}=1 \%$, the enhancement in the compressive strength was more significant when $V_{f}=2 \%$. The 28-day strength was considerably enhanced from $35 \mathrm{MPa}$ to $66 \mathrm{MPa}$ 
when $V_{f}$ was increased from $0 \%$ to $2 \%$. This could be attributed to the bridging of the propagating wing-cracks in the cementitious matrix by fibers under compression.

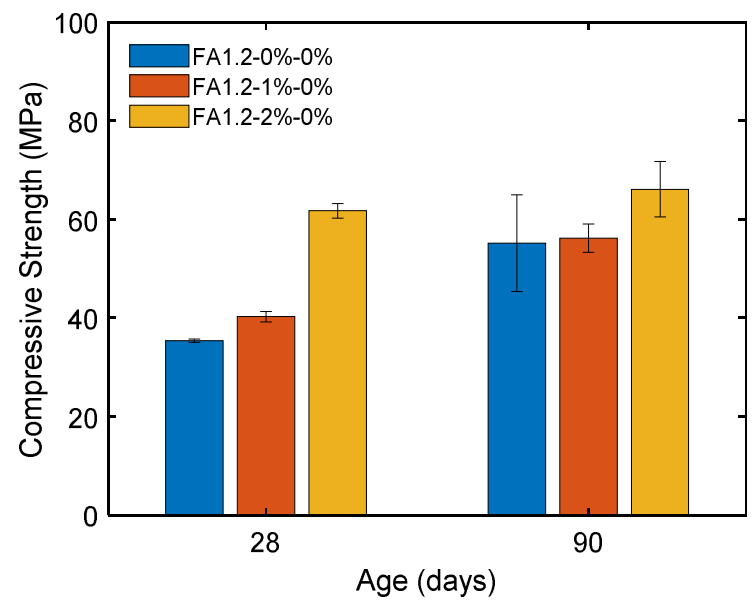

Figure 12. Compressive strengths of ECC with different amounts of fibers.

Figure 13 presents the influence of NLS content in the compressive strength of ECC at different ages. The early-age compressive strength (i.e., 7 days) was increased from $20 \mathrm{MPa}$ to $24 \mathrm{MPa}$ when the NLS content was increased from $0 \%$ to $2 \%$. This result suggests that when the degree of hydration was low, the formation of ettringite due to the inclusion of NLS filled the pores in the cement matrix and thus led to a denser microstructure. However, for the 28-day compressive strength, the inclusion of NLS resulted in a lower strength of ECC, with a reduction of up to $30 \%$. Arel and Aydin [73] indicated that the addition of NLS in cement leads to a reduced surface tension, which causes air entrainment and strength reduction. At 90 days, the strength development due to the pozzolanic reaction partially compensated the strength reduction due to air entrainment. The EECs with $0.5 \%$ of NLS achieved the lowest compressive strength at the 28-day and 90-day compared to other specimens. As discussed above, the LS consumption would be the highest at $0.5 \%$ NLS dosage among the considered mixtures. The semipermeable layer on the cement grains formed by the LS anions could slow down the migration of pore solution [66] and thus reduce the rate of cement hydration and the subsequent pozzolanic reaction. The slowed cement hydration could be again evident from the least development of the autogenous shrinkage of FA1.2-0.5\% as shown in Figure 10. The decreased rate of cement hydration could be the cause of the reduced compressive strengths.

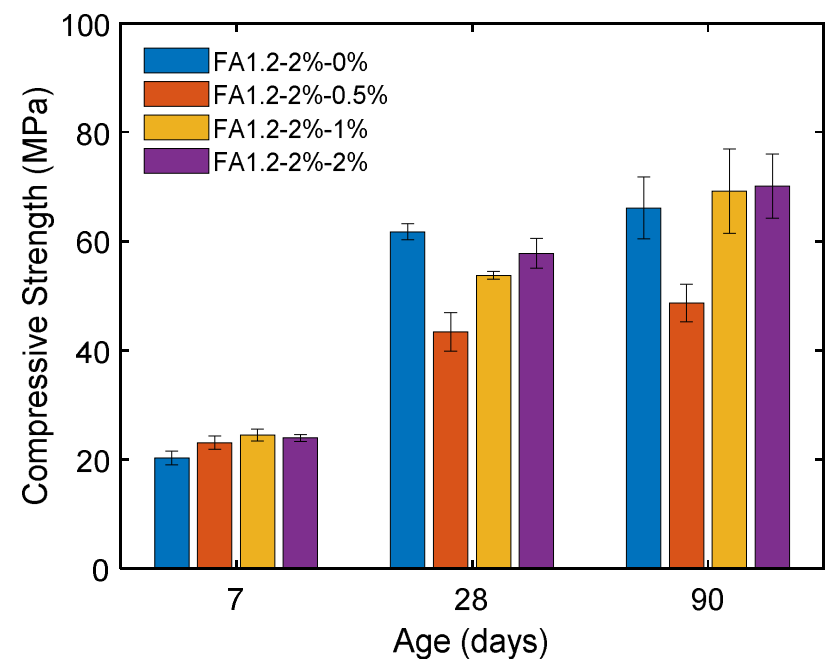

Figure 13. Influence of NLS on the compressive strength of ECC at different ages. 


\subsubsection{Tensile Strength}

Figure 14 shows the representative 28-day tensile stress-strain relationships for the ECC specimens with $V_{f}=2 \%$. It can be seen that ECC specimens exhibited tensile strain hardening behavior regardless of the FA and NLS contents. The 28-day tensile strength and strain capacities of ECC under the influences of FA/C ratio, fiber content, and NLS content are plotted in Figure 15. It can be seen in Figure 15a that although increasing the FA/C ratio from 1.2 to 2.2 reduced the tensile strength from $3.0 \mathrm{MPa}$ to $2.0 \mathrm{MPa}$ due to the lower cement content, it substantially enhanced the tensile strain capacity from $1.5 \%$ to $7.0 \%$ due to the reduced interfacial bond between fibers and the surrounding matrix [25]. Figure $15 \mathrm{~b}$ shows that the tensile strength of ECC was effectively enhanced from 1.4 to 3.0 MPa when $V_{f}$ was increased from 0 to $2 \%$. However, the higher tensile strength due to the increased $V_{f}$ from $1 \%$ to $2 \%$ slightly degraded the tensile strain capacity.

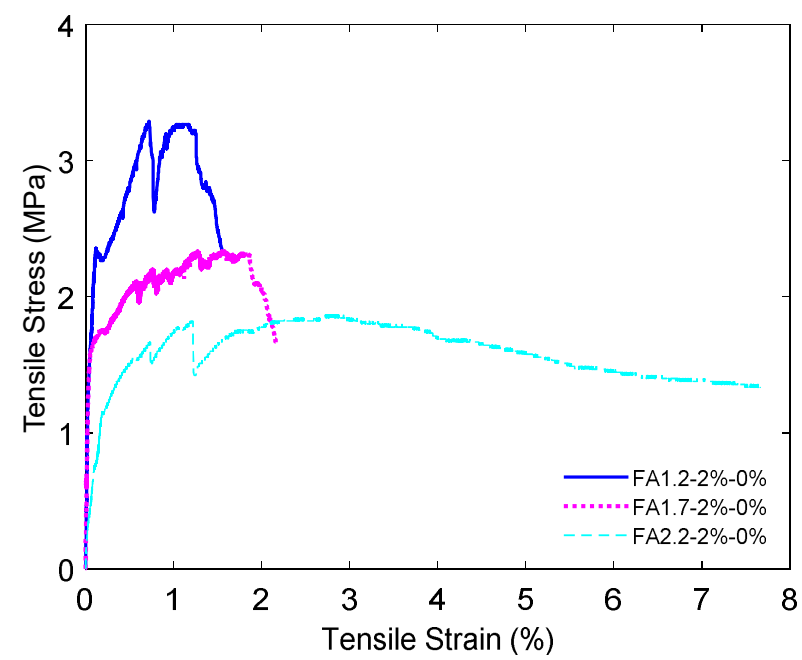

(a)

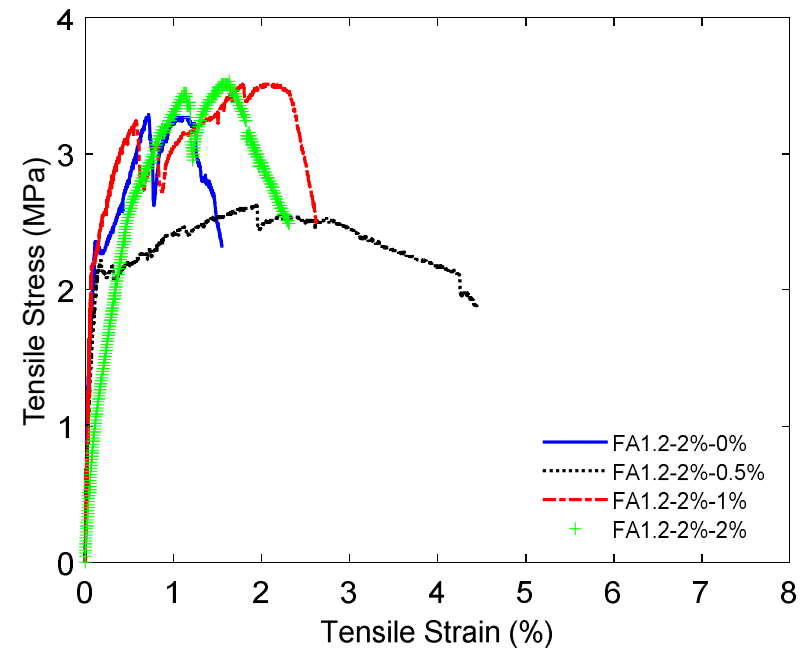

(b)

Figure 14. Tensile stress-strain relationships for ECC with $V_{f}=2 \%$ : (a) Different FA contents; (b) Different NLS contents. 


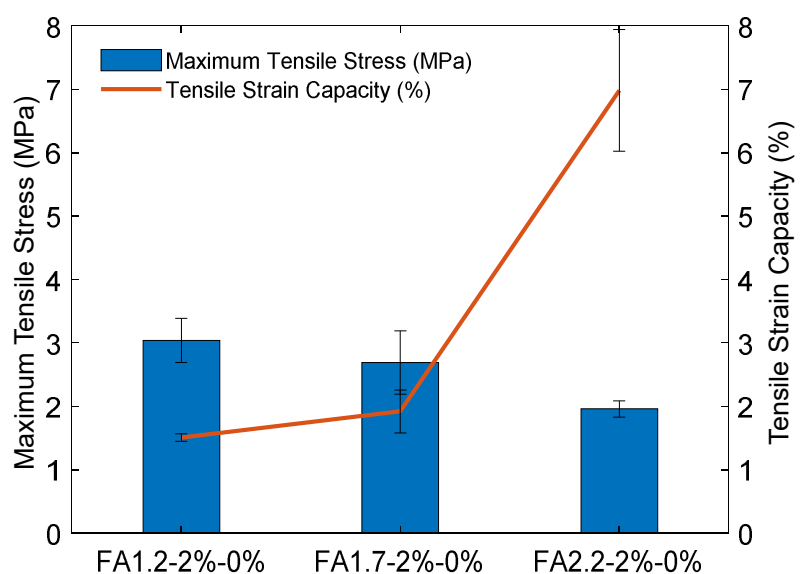

(a)

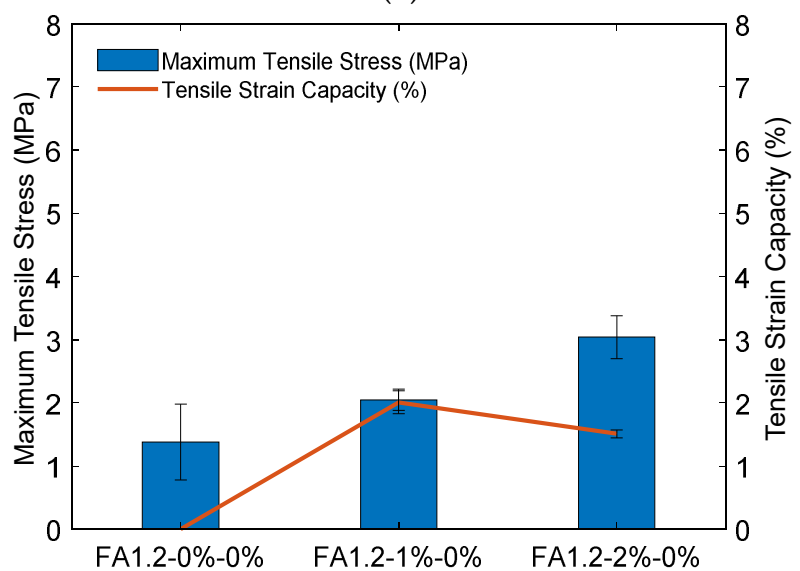

(b)

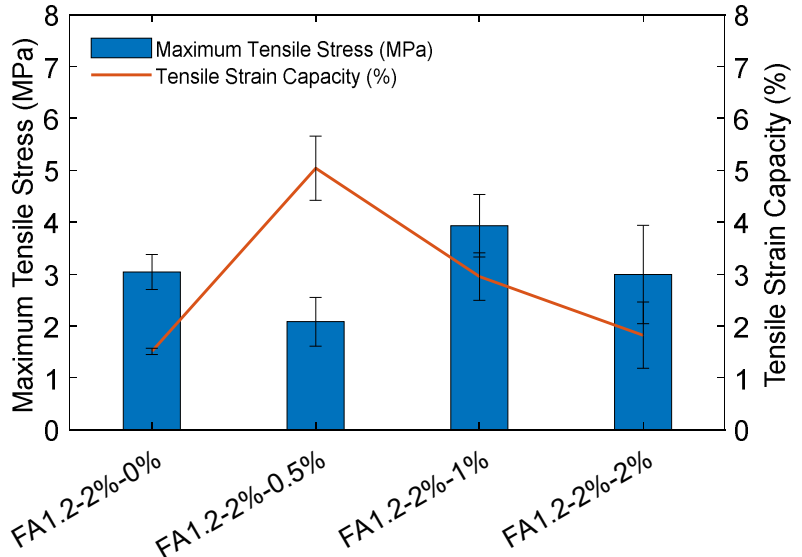

(c)

Figure 15. 28-day tensile strengths and strain capacities of ECC specimens: (a) Influence of FA content; (b) Influence of fiber content; (c) Influence of NLS content.

Figure $15 \mathrm{c}$ shows that increasing the NLS content from 0 to $2 \%$ did not cause significant influence in the tensile strength of ECC, likely because the tensile strength was mainly impacted by the bridging effect of fibers and the amount of C-S-H gels. As for the strain capacity, a small dosage of $0.5 \%$ NLS considerably enhanced the result from $1.5 \%$ to $5.0 \%$ This is likely due to the reduced strength and toughness of the cementitious matrix. As a result, the fracture energy required for crack initiation was reduced and thus promoting the multiple cracking behavior and the associated strain capacity. However, when the amount of NLS was further increased to $2 \%$, the strain capacity of ECC degraded to $1.8 \%$. 
This could be because the increased NLS content accelerated ettringite formation, which reduced the cohesiveness of the matrix and caused volumetric instability of the matrix [65].

\section{Conclusions}

The study showed that the initial and final setting times increased along with the NLS content of up to $1.0 \%$ and then remained relatively stable with a further higher NLS content to $2.0 \%$. The development of HVFA-ECC's drying shrinkage was governed by the first 14 days, and the autogenous shrinkage consistently developed for more than 28 days regardless of the fly ash content. Other important findings can be summarized as below.

(1) While the drying shrinkage of ECC was slightly increased with the higher FA/C ratio and fiber content, it was reduced by approximately $10 \%$ after the inclusion of NLS at $0.5 \%$. However, the beneficial influence of NLS in reducing the drying shrinkage gradually decreased with the further higher NLS content.

(2) The inclusion of $0.5 \%$ NLS led to the least autogenous shrinkage and strengths, which could have resulted from the largest LS uptake by cement grains among the considered mixtures that slowed the cement hydration.

(3) Increasing the FA/C ratio from 1.2 to 2.2 reduced the 28-day comprehensive strength of ECC by about $60 \%$. At 90 days, the low early-strength due to the use of a high FA/C ratio was partially compensated by the strength development due to the pozzolanic reaction. Moreover, when $V_{f}$ was increased from $0 \%$ to $2 \%$, the 28-day compressive strength was considerably increased from $35 \mathrm{MPa}$ to $62 \mathrm{MPa}$.

(4) Contrary to the negative impact on the strength, increasing the FA/C ratio from 1.2 to 2.2 substantially enhanced the tensile strain capacity of ECC by about five times. Furthermore, while the inclusion of NLS generally had minor influence in the tensile strength of ECC, it considerably enhanced the tensile strain capacity of ECC by more than two folds. Particularly, the inclusion of NLS at $0.5 \%$ led to the optimal enhancement in the tensile strain capacity, which was enhanced from $1.5 \%$ to $5.0 \%$.

(5) The 7-day compressive strength of ECC was increased by about $20 \%$ after the inclusion of NLS. However, for the 28-day compressive strength, the inclusion of NLS resulted in a lower strength of ECC, with a reduction of up to $30 \%$. At 90 days, the strength development due to the pozzolanic reaction helped compensate the strength reduction due to the formation of ettringite when NLS was present.

Author Contributions: Conceptualization, C.-C.H. and R.-C.S.; methodology, C.-C.H.; validation, A.T.A., C.-C.H., T.Y.P.Y. and R.-C.S.; formal analysis, A.T.A., T.Y.P.Y. and R.-C.S.; investigation, A.T.A., C.-C.H., T.Y.P.Y. and R.-C.S.; resources, C.-C.H.; data curation, A.T.A. and R.-C.S.; writing-original draft preparation, A.T.A., C.-C.H., T.Y.P.Y. and R.-C.S.; writing-review and editing, A.T.A., C.-C.H. and T.Y.P.Y.; visualization, A.T.A. and R.-C.S.; supervision, C.-C.H.; project administration, C.-C.H.; funding acquisition, C.-C.H. All authors have read and agreed to the published version of the manuscript.

Funding: This study was sponsored in part by the Ministry of Science and Technology, Taiwan, under Grant No. 109-2636-E-006-015.

Institutional Review Board Statement: Not applicable.

Informed Consent Statement: Not applicable.

Data Availability Statement: The raw data required to reproduce these findings cannot be shared at this time due to time limitations. The processed data required to reproduce these findings cannot be shared at this time due to time limitations.

Acknowledgments: The fellowship provided by the Foundation for the Advancement of Outstanding Scholarship is also greatly appreciated. The opinions, findings, and conclusions expressed in this paper are those of the authors, and do not necessarily reflect those of the sponsors.

Conflicts of Interest: The authors declare no conflict of interest. 


\section{References}

1. Naaman, A.E.; Reinhardt, H.W. Characterization of high-performance fiber reinforced cement composites. In Proceedings of the 2nd International Workshop on High Performance Fiber Reinforced Cement Composites: HPFRCC 2, RILEM, Ann Arbor, MI, USA, 11-14 June 1995; Naaman, A.E., Reinhardt, H.W., Eds.; E and FN Spon: New York, NY, USA, 1996; pp. 1-24.

2. Hung, C.-C.; El-Tawil, S. Seismic behavior of a coupled wall system with HPFRC materials in critical regions. J. Struct. Eng. 2011, 137, 1499-1507. [CrossRef]

3. Hung, C.-C.; Chen, Y.T.; Yen, C.H. Workability, fiber distribution, and mechanical properties of UHPC with hooked end steel macro-fibers. Constr. Build. Mater. 2020, 260, 119944. [CrossRef]

4. Lequesne, R.D.; Setkit, M.; Parra-Montesinos, G.J.; Wight, J.K. Seismic detailing and behavior of coupling beams with highperformance fiber reinforced concrete. In Antoine E. Naaman Symposium: Four Decades of Progress in Prestressed Concrete, Fiber Reinforced Concrete and Thin Laminate Composites; SP-272; American Concrete Institute: Farmington Hills, MI, USA, 2010; pp. 189-204.

5. Hung, C.-C.; Hsieh, P.-L. Comparative study on shear failure behavior of squat high-strength steel reinforced concrete shear walls with various high-strength concrete materials. Structures 2020, 23, 56-68. [CrossRef]

6. Hung, C.-C.; Lee, H.-S.; Chan, S.N. Tension-stiffening effect in steel-reinforced UHPC composites: Constitutive model and effects of steel fibers, loading patterns, and rebar sizes. Compos. Part B Eng. 2019, 158, 269-278. [CrossRef]

7. Hung, C.-C.; Chueh, C.-Y. Cyclic behavior of UHPFRC flexural members reinforced with high-strength steel rebar. Eng. Struct. 2016, 122, 108-120. [CrossRef]

8. Yang, J.; Fischer, G. Investigation of the fiber bridging stress-crack opening relationship of fiber reinforced cementitious composite. In International RILEM Workshop on High Performance Fiber Reinforced Cement Composites in Structural Applications; Fischer, G., Li, V.C., Eds.; RILEM Publications SARL: Bagneux, France, 2006; pp. 93-105.

9. Naaman, A.E.; Reinhardt, H.W. Report of the RILEM International Workshop on High Performance Fiber Reinforced Cement Composites (HPFRCC-4)-Ann Arbor, Michigan, 16-18 June 2003. Mater. Struct. 2003, 36, 710-712. [CrossRef]

10. Rapoport, J.; Aldea, C.M.; Shah, S.P.; Ankenman, B.; Karr, A.F. Permeability of cracked steel fiber-reinforced concrete. J. Mater. Civ. Eng. 2002, 14, 355-358. [CrossRef]

11. Lee, B.J.; Hyun, J.H.; Kim, Y.Y.; Shin, K.J. Chloride permeability of damaged high-performance fiber reinforced cement composite by repeated compressive loads. Materials 2014, 7, 5802-5815. [CrossRef]

12. Fischer, G.; Li, V.C. Effects of matrix ductility on the deformation behavior of steel-reinforced ECC flexural members under reversed cyclic loading conditions. ACI Struct. J. 2020, 99, 781-790.

13. Hung, C.-C.; Hung, H.-H. Potential of sodium sulfate solution for promoting the crack-healing performance for strain-hardening cementitious composites. Cem. Concr. Compos. 2020, 106, 103461. [CrossRef]

14. Li, V.C. Tailoring ECC for special attributes: A review. Int. J. Concr. Struct. Mater. 2012, 6, 135-144. [CrossRef]

15. Hung, C.-C.; Su, Y.F.; Su, Y.M. Mechanical properties and self-healing evaluation of strain-hardening cementitious composites with high volumes of hybrid pozzolan materials. Compos. Part. B Eng. 2018, 133, 15-25. [CrossRef]

16. Olsen, E.C.; Billington, S.L. Cyclic response of precast high-performance fiber-reinforced concrete infill panels. ACI Struc. J. 2011, 108, 51-60. [CrossRef]

17. Hung, C.-C.; Chen, Y.S. Innovative ECC jacketing for retrofitting shear-deficient RC members. Constr. Build. Mater. 2016, 111, 408-418. [CrossRef]

18. Hung, C.-C.; Yen, W.M.; Yu, K.H. Vulnerability and improvement of reinforced ECC flexural members under displacement reversals: Experimental investigation and computational analysis. Constr. Build. Mater. 2016, 107, 287-298. [CrossRef]

19. Liu, H.; Zhang, Q.; Gu, C.; Su, H.; Li, V.C. Influence of microcrack self-healing behavior on the permeability of engineered cementitious composites. Cement Concr. Compos. 2017, 82, 14-22. [CrossRef]

20. Lepech, M.D.; Li, V.C. Water permeability of engineered cementitious composites. Cement Concr. Compos. 2009, 31, 744-753. [CrossRef]

21. Yu, K.; Wang, Y.; Yu, J.; Xu, S. A strain-hardening cementitious composites with the tensile capacity up to $8 \%$. Constr. Build. Mater. 2017, 137, 410-419. [CrossRef]

22. Zhou, Y.; Xi, B.; Yu, K.; Sui, L.; Xing, F. Mechanical properties of hybrid ultra-high performance engineered cementitous composites incorporating steel and poly-ethylene fibers. Materials 2018, 11, 1448. [CrossRef] [PubMed]

23. Zhou, Y.; Xi, B.; Sui, L.; Zheng, S.; Xing, F.; Li, L. Development of high strain-hardening light weight engineered cementitious composites: Design and performance. Cement Concr. Compos. 2019, 104, 103370. [CrossRef]

24. Hung, C.-C.; Su, Y.-F.; Hung, H.-H. Impact of natural weathering on medium-term self-healing performance of fiber reinforced cementitious composites with intrinsic crack-width control capability. Cement Concr. Compos. 2017, 80, 200-209. [CrossRef]

25. Hung, C.-C.; Su, Y.-F. Medium-term self-healing evaluation of engineered cementitious composites with varying amounts of fly ash and exposure durations. Constr. Build. Mater. 2016, 118, 194-203. [CrossRef]

26. Qudah, S.; Maalej, M. Application of Engineered Cementitious Composites (ECC) in interior beam-column connections for enhanced seismic resistance. Eng. Struct. 2014, 69, 235-245. [CrossRef]

27. Nath, P.; Sarker, P.K. Effect of mixture proportions on the drying shrinkage and permeation properties of high strength concrete containing class F fly ash. KSCE J. Civ. Eng. 2013, 17, 1437-1445. [CrossRef] 
28. Mao, X.Q.; Zhao, T.J.; Zhang, P. Optimization of shrinkage and crack resistance performance of Engineered Cementitious Composites (ECC). In Proceedings of the 2011 International Conference on Electric Technology and Civil Engineering (ICETCE), Lushan, China, 22-24 April 2011; pp. 534-538.

29. Güneyisi, E.; Gesoğlu, M.; Karaoğlu, S.; Mermerdaş, K. Strength, permeability and shrinkage cracking of silica fume and metakaolin concretes. Constr. Build. Mater. 2012, 34, 120-130. [CrossRef]

30. Hung, C.-C.; El-Tawil, S. Hybrid rotating/fixed-crack model for high-performance fiber-reinforced cementitious composites. ACI Mater. J. 2010, 107, 569-577. [CrossRef]

31. Vasconez, R.M.; Naaman, A.E.; Wight, J.K. Behavior of HPFRC connections for precast concrete frames under reversed cyclic loading. PCI J. 1998, 43, 58-71. [CrossRef]

32. Hung, C.-C.; Li, H.; Chen, H.-C. High-strength steel reinforced squat UHPFRC shear walls: Cyclic behavior and design implications. Eng. Struct. 2017, 141, 59-74. [CrossRef]

33. Hung, C.-C.; Su, Y.-F.; Yu, K.H. Modeling the shear hysteretic response for high performance fiber reinforced cementitious composites. Constr. Build. Mater. 2013, 41,37-48. [CrossRef]

34. Hung, C.-C.; Li, S.H. Three-dimensional model for analysis of high performance fiber reinforced cement-based composites. Compos. Part. B Eng. 2013, 45, 1441-1447. [CrossRef]

35. Savino, V.; Lanzoni, L.; Tarantino, A.M.; Viviani, M. Simple and effective models to predict the compressive and tensile strength of HPFRC as the steel fiber content and type changes. Compos. Part. B Eng. 2018, 137, 153-162. [CrossRef]

36. Sujivorakul, C.; Naaman, A.E. Tensile response of HPFRC composites using twisted polygonal steel fibers. Spec. Publ. 2003, 216, 161-180.

37. Naaman, A.E.; Reinhardt, H.W. Proposed classification of HPFRC composites based on their tensile response. Mater. Struct. 2006, 39, 547-555. [CrossRef]

38. Hung, C.-C.; Hu, F.-Y. Behavior of high-strength concrete slender columns strengthened with steel fibers under concentric axial loading. Constr. Build. Mater. 2018, 175, 422-433. [CrossRef]

39. Hung, C.-C.; Hu, F.-Y.; Yen, C.-H. Behavior of slender UHPC columns under eccentric loading. Eng. Struct. 2018, 174, 701-711. [CrossRef]

40. Sahmaran, M.; Li, V.C. Durability properties of micro-cracked ECC containing high volumes fly ash. Cement Concr. Res. 2009, 39, 1033-1043. [CrossRef]

41. Zhang, J.; Gong, C.; Guo, Z.; Zhang, M. Engineered cementitious composite with characteristic of low drying shrinkage. Cem. Concr. Res. 2009, 39, 303-312. [CrossRef]

42. Wang, S.; Li, V.C. Engineered cementitious composite with high volume fly ash. ACI Mater. J. 2007, 104, 233-241. [CrossRef]

43. Hewlett, P.C.; Justnes, H.; Edmeades, R.M. Cement and concrete admixtures. In Lea's Chemistry of Cement and Concrete, 5th ed.; Elsevier: Amsterdam, The Netherlands, 2019; pp. 641-698.

44. Ramachandran, V.S.; Paroli, R.M.; Beaudoin, J.J.; Delgado, A.H. Handbook of Thermal Analysis of Construction Materials; William Andrew Publishing: Norwich, NY, USA, 2002.

45. Collepardi, M. The world of chemical admixtures in concrete. In Proceedings of the 18th Congress on Our World in Concrete and Structures, Singapore, 25-27 August 1993; pp. 63-72.

46. Satiyawira, B.; Fathaddin, M.T.; Setiawan, R. Effects of lignosulfonate and temperature on compressive strength of cement. In Proceedings of the World Geothermal Congress, Bali, Indonesia, 25-29 April 2010; pp. 1-3.

47. Arel, H.S. The effect of lignosulfonates on concretes produced with cements of variable fineness and calcium aluminate content. Constr. Build. Mater. 2017, 131, 347-360. [CrossRef]

48. Skripkiunas, G.; Rudzionis, Z.; Vaitkevicius, V. Complex admixtures for high-strength concrete. J. Civ. Eng. Manag. 2002, 8, 276-280. [CrossRef]

49. Mohammed, T.U.; Ahmed, T.; Apurbo, S.M.; Mallick, T.A.; Shahriar, F.; Munim, A.; Awal, M.A. Influence of chemical admixtures on fresh and hardened properties of prolonged mixed concrete. Adv. Mater. Sci. Eng. 2017, 2017, 9187627. [CrossRef]

50. Topcu, I.B.; Atesin, O. Effect of high dosage lignosulphonate and naphthalene sulphonate based plasticizer usage on micro concrete properties. Constr. Build. Mater. 2016, 120, 189-197. [CrossRef]

51. Lauten, R.A.; Myrvold, B.O.; Gundersen, S.A. New Developments in the Commercial Utilization of Lignosulfonates, in Surfactants from Renewable Resources; John Wiley and Sons: Hoboken, NJ, USA, 2010; pp. 269-283.

52. Danner, T.; Justnes, H.; Geiker, M.; Lauten, R.A. Phase changes during the early hydration of Portland cement with Calignosulfonates. Cem. Concr. Res. 2015, 69, 50-60. [CrossRef]

53. Yousuf, M.; Mollah, A.; Lu, F.; Schennach, R.; Cocke, D.L. An X-ray diffraction, fourier-transform infrared spectroscopy, and scanning electron microscopy/energy-dispersive spectroscopic investigation of the effect of sodium lignosulfonate superplasticizer on the hydration of Portland cement type V. Polym. Plast. Technol. Eng. 1999, 38, 849-868. [CrossRef]

54. Vikan, H. Rheology and Reactivity of Cementitious Binders with Plasticizers. Ph.D. Thesis, Norwegian University of Science and Technology (NTNU), Trondheim, Norway, 2005.

55. Cabrera, J.G.; Cusens, A.R.; Brookes-Wang, Y. Effect of superplasticizers on the plastic shrinkage of concrete. Mag. Concr. Res. 1992, 44, 149-155. [CrossRef]

56. Colombo, A.; Geiker, M.; Justnes, H.; Lauten, R.A.; De Weerdt, K. On the mechanisms of consumption of calcium lignosulfonate by cement paste. Cem. Concr. Res. 2017, 98, 1-9. [CrossRef] 
57. ASTM International. ASTM C403/C403M-08: Standard Test. Method for Time of Setting of Concrete Mixtures by Penetration Resistance; ASTM International: West Conshohocken, PA, USA, 2008.

58. ASTM International. ASTM C490/C490M-17: Standard Practice for Use of Apparatus for Determination of Length Change of Hardened Cement Paste Mortar and Concrete; ASTM International: West Conshohocken, PA, USA, 2017.

59. ASTM International. ASTM C39/C39M-20: Standard Test. Method for Compressive Strength of Cylindrical Concrete Specimens; ASTM International: West Conshohocken, PA, USA, 2020.

60. Japan Society of Civil Engineers (JSCE). Recommendations for Design and Construction of High.-Performance Fiber Reinforced Cement Composites with Multiple Fine Cracks (HPFRCC); Japan Society of Civil Engineers: Tokyo, Japan, 2008.

61. Rao, G.A. Influence of silica fume replacement of cement on expansion and drying shrinkage. Cem. Concr. Res. 1998, 28, 1505-1509. [CrossRef]

62. Mokarem, D.W.; Weyers, R.E.; Lane, D.S. Development of a shrinkage performance specifications and prediction model analysis for supplemental cementitious material concrete mixtures. Cem. Concr. Res. 2005, 35, 918-925. [CrossRef]

63. Boshoff, W.P.; Van Zijl, G.P.A.G. Tensile creep of SHCC. In Proceedings of the International RILEM Conference on High Performance Fiber Reinforced Cement Composites (HPFRCC 5), Mainz, Germany, 10-13 July 2007; pp. 87-95.

64. Guerini, V.; Conforti, A.; Plizzari, G.; Kawashima, S. Influence of steel and macro-synthetic fibers on concrete properties. Fibers 2018, 6, 47. [CrossRef]

65. Piasta, W.; Sikora, H. Effect of air entrainment on shrinkage of blended cements concretes. Constr. Build. Mater. 2015, 99, 298-307. [CrossRef]

66. Bishop, M.; Barron, A.R. Cement hydration inhibition with sucrose, tartaric acid, and lignosulfonate: Analytical and spectroscopic study. Ind. Eng. Chem. Res. 2006, 45, 7042-7049. [CrossRef]

67. Jiang, L.; Guan, Y. Pore structure and its effect on strength of high-volume fly ash paste. Cem. Concr. Res. 1999, 29, 631-633. [CrossRef]

68. Li, Y.; Bao, J.; Guo, Y. The relationship between autogenous shrinkage and pore structure of cement paste with mineral admixture. Constr. Build. Mater. 2010, 24, 1855-1860. [CrossRef]

69. Singh, N.B.; Kumar, M.; Mishra, P.K.; Singh, N.P.; Singh, S.K. Effect of polyvinyl alcohol on hydration of fly ash blended cement. ACI Mater. J. 2014, 111, 673-680. [CrossRef]

70. Yu, R.; Spiesz, P.; Brouwers, H.J.H. Mix design and properties assessment of Ultra-High Performance Fibre Reinforced Concrete (UHPFRC). Cem. Concr. Res. 2014, 56, 29-39. [CrossRef]

71. Mezhov, A.; Kovler, K. Effect of sodium lignosulfonate superplasticizer on the early hydration of cement with different contents of cubic C3A. IOP Conf. Ser. Mater. Sci. Eng. 2019, 660, 012037. [CrossRef]

72. Kim, G.; Lee, E.; Koo, K. Hydration heat and autogenous shrinkage of high-strength mass concrete. J. Asian Archit. Build. Eng. 2018, 8, 509-516. [CrossRef]

73. Arel, H.S.; Aydin, E. Effects of Ca-, Mg-, K-, and Na-lignosulfonates on the behavior of fresh concrete. Constr. Build. Mater. 2017, 157, 1084-1091. [CrossRef] 